\title{
Sterol Synergism in Paramecium tetraurelia
}

\author{
By BRUCE D. WHITAKER† AND DAVID L. NELSON* \\ Department of Biochemistry, University of Wisconsin-Madison, College of Agricultural and Life \\ Sciences, 420 Henry Mall, Madison, WI 53706, USA
}

(Received 26 January 1988)

\begin{abstract}
Paramecium tetraurelia is a naturally occurring sterol auxotroph with an absolute nutritional requirement for one of a small group of structurally related phytosterols. We report here a quantitative study demonstrating that a low, otherwise sub-supportive, concentration $(\approx 0.020$ $0.050 \mu \mathrm{g} \mathrm{ml}^{-1}$ ) of an essential phytosterol (stigmasterol) is adequate for growth of this ciliate, provided that a second, relatively non-specific sterol is available at a higher concentration $\left(1.0 \mu \mathrm{g} \mathrm{ml}^{-1}\right)$ to allow for membrane biosynthesis. This phenomenon, referred to as sterol synergism, has been observed in a broad taxonomic range of organisms, with the conclusion that small amounts of specific sterols are required to perform some previously unknown, vital metabolic or regulatory function. Paramecium promises to be an excellent model organism for the elucidation of essential sterol function.
\end{abstract}

\section{INTRODUCTION}

Ciliated protozoans of the genus Paramecium are auxotrophic for a phytosterol and octadecenoic acid (van Wagtendonk et al., 1953; Soldo \& van Wagtendonk, 1967). The nutritional requirement for sterol was described 30 years ago, when it was found that only a small group of structurally similar phytosterols support growth (Conner et al., 1953; Conner \& van Wagtendonk, 1955). One subsequent report has addressed the question of why specific phytosterols are required for growth of Paramecium (Conner et al., 1971). An apparent link between growth support and fatty acyl esterification of sterols was demonstrated. Our recent study of the metabolism of phytosterols in Paramecium tetraurelia (Whitaker \& Nelson, 1987) revealed that non-growth-supporting sterols are esterified and can constitute a high percentage of the cell's esterified sterols when growth support is conferred by a phytosterol other than stigmasterol. In addition, we have demonstrated the phenomenon of sterol synergism or sparing in this simple eukaryote, i.e. the adequacy of non-growth-supporting sterols for the cell's bulk membrane structural requirement when a much lower concentration of an essential phytosterol is provided to meet the nutritional requirement (Pinto et al., 1983; Rampogal \& Bloch, 1983; Whitaker \& Nelson, 1987).

Over the past decade, sterol synergism has been described and characterized in a variety of organisms, including microbes, invertebrates and vertebrates, summarized in a review by Bloch (1983). Among the micro-organisms are the prokaryote Mycoplasma, several yeasts and Tetrahymena. The general conclusion from these studies is that, in addition to the relatively nonspecific requirement for sterols as a structural component of cell membranes, there is often a requirement for small amounts of specific sterols which apparently perform some vital metabolic or regulatory function.

Paramecium offers several clear advantages for research directed toward the elucidation of essential sterol function: (1) it is a simple, single-celled eukaryotic micro-organism which is

† Present address: USDA-ARS BARC-W, Horticultural Crops Quality Laboratory, Building 002, Room 202, Beltsville, MD 20705, USA. 
naturally auxotrophic for sterols; (2) it grows well in both a defined (but complex) axenic medium and a simple monoxenic medium consisting of a dense suspension of Escherichia coli plus added sterol in a buffered salts solution (Whitaker \& Nelson, 1987); and (3) mutants are readily generated and selected, and the genetics is well understood. In this study we have quantified the synergistic effect of combinations of growth-supporting and non-growthsupporting sterols on the growth of $P$. tetraurelia in both axenic and monoxenic cultures.

Table 1. Source and purity of sterols

\begin{tabular}{|c|c|c|c|c|}
\hline Sterol & Carbon no. & $R$ group at $C-24$ & Source & $\begin{array}{c}\text { Purity* } \\
(\%)\end{array}$ \\
\hline $\begin{array}{l}\text { Stigmasterol } \\
\text { (stigmasta-5,22-dien-3 } \beta \text {-ol) }\end{array}$ & 29 & $\alpha-C_{2} H_{5}$ & Applied Science Labs & 98 \\
\hline $\begin{array}{l}\text { Cholesterol } \\
\text { (cholest-5-en-3 } \beta \text {-ol) }\end{array}$ & 27 & $-\mathbf{H}$ & Sigma & $99+$ \\
\hline $\begin{array}{l}\text { Campesterol } \\
\text { ([24R]-ergost-5-en-3 } \beta \text {-ol) }\end{array}$ & 28 & $\alpha-\mathrm{CH}_{3}$ & Sigma & 99 \\
\hline $\begin{array}{l}\text { Ergosterol } \\
\text { (ergosta-5,7,22-trien-3 } \beta \text {-ol) }\end{array}$ & 28 & $\beta-\mathrm{CH}_{3}$ & Aldrich & 98 \\
\hline Tetrahymanol & $30 \dagger$ & - & Tetrahymena pyriformis & 99 \\
\hline
\end{tabular}

\section{METHODS}

Cultures. Wild-type strain 51S of Paramecium tetraurelia (Sonneborn, 1975) was used throughout this study. In the first series of experiments, cells were grown in monoxenic culture in a medium devised to eliminate the problem of sterol contaminants. This medium consisted of a dense suspension of Escherichia coli $\mathrm{B}$ in a solution containing $15 \mathrm{~mm}$-MOPS buffer, $3 \mathrm{mM}-\mathrm{KCl}$ and $1 \mathrm{mM}-\mathrm{CaCl}_{2}$. The $\mathrm{pH}$ of the MOPS basal medium was raised to 6.2 with $\mathrm{KOH}$ and finally to 6.5 with $\mathrm{NaOH}$. Sterols were added in an ethanolic solution to the MOPS basal medium prior to autoclaving. $E$. coli was grown in minimal glucose medium to stationary phase, harvested by centrifugation, washed once and resuspended in a small volume of sterile MOPS basal medium. Equal volumes of this suspension were then pipetted into each culture flask prior to inoculation with $P$. tetraurelia. This method of culturing Paramecium has been described in greater detail elsewhere (Whitaker \& Nelson, 1987).

In the second series of experiments $P$. tetraurelia 51S was grown in Soldo's crude axenic medium (Soldo \& van Wagtendonk, 1969). This medium is based on proteose and trypticase peptone plus yeast nucleic acid; it is rich in vitamins and unesterified fatty acids $\left(\approx 45 \mu \mathrm{g} \mathrm{ml}^{-1}\right)$, and includes $1-\alpha$-cephalin (phosphatidylethanolamine) with a high polyunsaturated fatty acid content. The latter component of the medium included a substantial amount of cholesterol as a contaminant, and therefore was purified by silicic acid column chromatography (Whitaker $\&$ Nelson, 1987) prior to use. The desired combinations of bulk sterols plus stigmasterol were added in ethanolic solution prior to autoclaving culture flasks containing the axenic medium.

Commercial and natural sources of sterols. Table 1 presents the source and purity of sterols used in this study. With the exception of the pentacyclic triterpenoid alcohol tetrahymanol, all sterols were acquired from commercial sources and were recrystallized once or twice from hot $100 \%$ ethanol prior to use. Tetrahymanol was isolated from the ciliated protozoan Tetrahymena pyriformis and purified as reported previously (Whitaker \& Nelson, 1987).

\section{RESULTS}

\section{Requirement for exogenous sterol}

Fig. 1 depicts the influence of exogenous stigmasterol concentration on the growth of $P$. tetraurelia in monoxenic culture. In these experiments, stigmasterol and its metabolite, 7-dehydrostigmasterol (Conner et al., 1971; Whitaker \& Nelson, 1987), served as both the bulk membrane sterol and the nutritionally required phytosterol. Under this condition, near maximal growth was realized at an exogenous stigmasterol concentration of $5.0 \mu \mathrm{g} \mathrm{ml}^{-1}$ (Pitt, 1980). The maximum cell density attained in monoxenic cultures, and to a lesser extent the exponential rate of growth, decreased with decreasing sterol concentration. The minimum amount of 


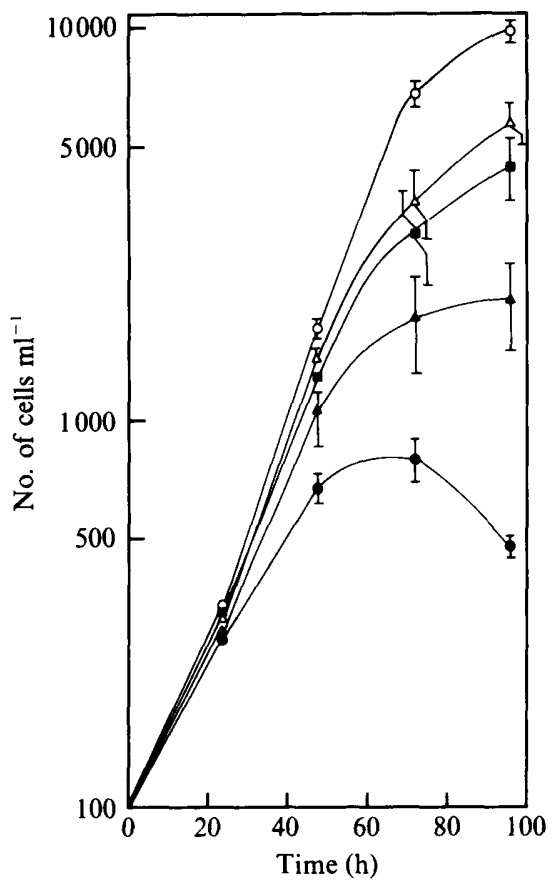

Fig. 1. Dependence of growth of $P$. tetraurelia at $28^{\circ} \mathrm{C}$ in monoxenic cultures on the exogenous stigmasterol concentration. Erlenmeyer flasks $(250 \mathrm{ml})$ containing $50 \mathrm{ml}$ sterile MOPS basal medium plus the specified concentration of stigmasterol and a dense suspension of $E$. coli B were inoculated at $\approx 100$ cells $\mathrm{ml}^{-1}$ at time zero. The inoculum was drawn from an early stationary-phase culture $(96 \mathrm{~h}$ growth; $\approx 5 \times 10^{3}$ cells ml-1) supplemented with $1.0 \mu \mathrm{g}$ stigmasterol $\mathrm{ml}^{-1}$. Vertical bars represent \pm 1 SD $(n=5)$. Stigmasterol was added at 5.0 (O), $2.0(\triangle), 1.0(\square), 0.5(\Delta)$ and $0.2(\bigcirc) \mu \mathrm{g} \mathrm{ml}^{-1}$.

stigmasterol required for significant growth, roughly three cell divisions during the $70 \mathrm{~h}$ postinoculation period, was $0 \cdot 2 \mu \mathrm{g} \mathrm{ml}^{-1}$. Below this level of stigmasterol supplementation $\leq$ one cell division occurred in $\geq 48 \mathrm{~h}$ (data not shown).

\section{Sterol synergism in monoxenic cultures}

We have previously reported that in monoxenic cultures supplemented with a high ratio of a non-growth-supporting sterol to stigmasterol ( $\geq 4: 1$ ), the non-growth-supporting sterol (and its dehydrogenated derivative, if any) generally constituted the majority of the unesterified (free) sterols in both whole cells and cell (ciliary) membranes (Whitaker \& Nelson, 1987). This did not hold true, however, for cultures supplemented with the triterpenoid alcohol tetrahymanol plus stigmasterol in a ratio of $10: 1$. While tetrahymanol did constitute the majority of the free sterols in whole cells from these cultures, it accounted for only $\approx 40 \%$ of the ciliary sterols. These and other data led us to conclude that tetrahymanol serves poorly as a structural component of the cell membrane of Paramecium, while $\Delta^{5,7}$-diene sterols are optimal in this role.

The results from this present, quantitative study of stigmasterol sparing by cholesterol and tetrahymanol in monoxenic cultures of $P$. tetraurelia (Figs 2 and 3) support our previous conclusion. In these experiments, the concentration of stigmasterol was varied over the range $0 \cdot 0-0 \cdot 25 \mu \mathrm{g} \mathrm{ml}^{-1}$, and the concentration of the sparing sterol (i.e. cholesterol or tetrahymanol) was held constant at $1.0 \mu \mathrm{g} \mathrm{ml}^{-1}$. At the maximum ratio of stigmasterol to sparing sterol $(1: 4$, or $0.25: 1.0 \mu \mathrm{m} \mathrm{ml}^{-1}$ ), both the exponential growth rate and maximum titre of cultures supplemented with cholesterol (Fig. 2) were substantially higher than those of comparable cultures supplemented with tetrahymanol (Fig. 3). In addition, the threshold ratio of 


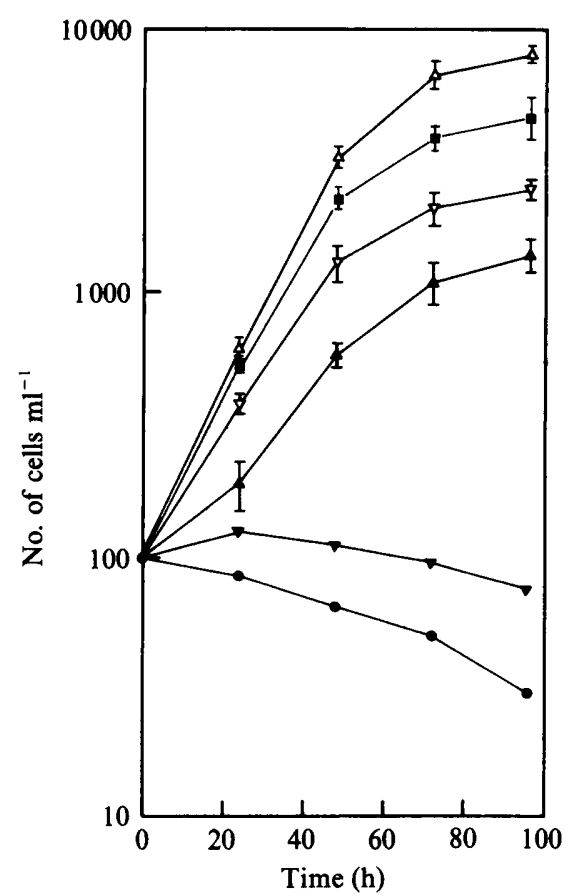

Fig. 2

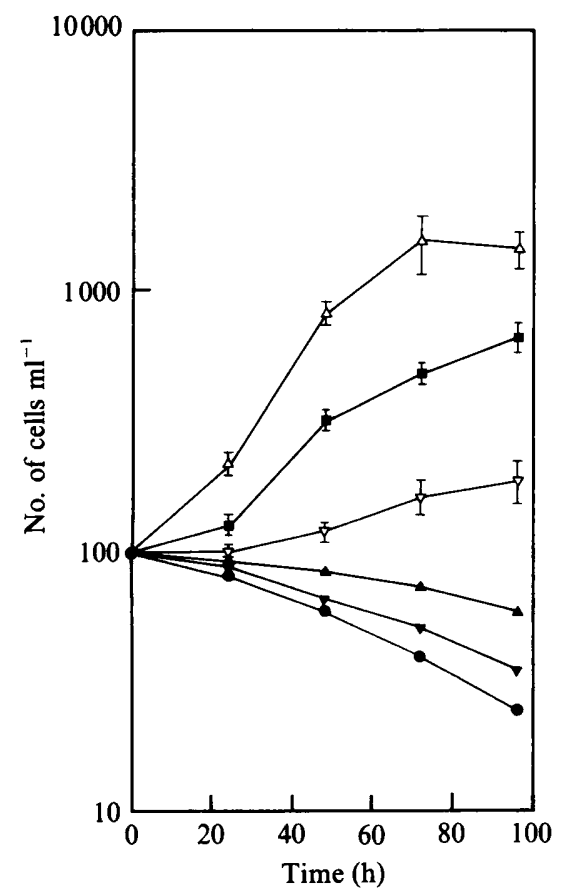

Fig. 3

Fig. 2. Sparing of the requirement for stigmasterol by cholesterol in monoxenic cultures of $P$. tetraurelia at $28^{\circ} \mathrm{C}$. Erlenmeyer flasks $(250 \mathrm{ml})$ containing $50 \mathrm{ml}$ sterile MOPS basal medium, the specified concentrations of a dense suspension of $E$. coli $\mathrm{B}$, cholesterol and stigmasterol were inoculated at $\approx 100$ cells ml $\mathrm{m}^{-1}$ at time zero. The inoculum $(\approx 0.7 \mathrm{ml})$ was drawn from an early stationary-phase culture $(96 \mathrm{~h}$ growth; $\approx 7 \times 10^{3}$ cells ml $^{-1}$ ) supplemented with $1.0 \mu \mathrm{g}$ cholesterol ml ${ }^{-1}$ plus $0.2 \mu \mathrm{g}$ stigmasterol ml ${ }^{-1}$. Vertical bars represent $\pm 1 \mathrm{SD}(n=3$, with replicate cultures in each experiment). SD was generally quite small at sub-supportive concentrations of stigmasterol, and is therefore not shown for these curves. Cholesterol at $1.0 \mu \mathrm{g} \mathrm{m}^{-1}(\mathrm{O})$; plus stigmasterol at $0.010(\nabla), 0.025(\Delta), 0.050(\nabla), 0.100(\mathbb{D})$ and $0.250(\triangle) \mu \mathrm{g} \mathrm{ml}^{-1}$. (See Fig. 1 for $1.0 \mu \mathrm{g}$ stigmasterol $\mathrm{ml}^{-1}$ control.)

Fig. 3. Sparing of the requirement for stigmasterol by tetrahymanol in monoxenic cultures of $P$. tetraurelia at $28^{\circ} \mathrm{C}$. Erlenmeyer flasks $(250 \mathrm{ml})$ containing $50 \mathrm{ml}$ sterile MOPS basal medium plus a dense suspension of $E$. coli $B$ and the specified concentrations of tetrahymanol and stigmasterol were inoculated at $\approx 100$ cells $\mathrm{ml}^{-1}$ at time zero. The inoculum $(\approx 3.3 \mathrm{ml})$ was drawn from an early stationary-phase culture $\left(96 \mathrm{~h}\right.$ growth; $\approx 1.5 \times 10^{3} \mathrm{cells}^{-1}$ ) supplemented with $1.0 \mu \mathrm{g}$ tetrahymanol $\mathrm{ml}^{-1}$ plus $0.2 \mu \mathrm{g}$ stigmasterol $\mathrm{ml}^{-1}$. (Thus, the actual concentration of stigmasterol in sparing experiments was $\approx 0.013 \mu \mathrm{g} \mathrm{ml}^{-1}$ higher than the specified concentration.) Vertical bars represent \pm 1 SD $\left(n=3\right.$, with replicate cultures in each experiment). Tetrahymanol at $1.0 \mu \mathrm{g} \mathrm{ml}^{-1}$ (O); plus stigmasterol at $0.010(\nabla), 0.025(\Delta), 0.050(\nabla), 0.100(\square)$ and $0.250(\Delta) \mu \mathrm{g} \mathrm{m}^{-1}$. (See Fig. 1 for $1.0 \mu \mathrm{g}$ stigmasterol $\mathrm{ml}^{-1}$ control.)

stigmasterol to sparing sterol (i.e. the lowest ratio allowing for measurable growth) was clearly lower in cultures supplemented with cholesterol $(\leq 1: 50)$ than in cultures supplemented with tetrahymanol $(\approx 1: 20)$.

\section{Sterol synergism in axenic cultures}

We have also done a quantitative study of stigmasterol sparing in axenic cultures by campesterol, ergosterol and cholesterol (Figs 4, 5 and 6, respectively). The data indicate a distinct order of effectiveness with respect to growth rate and maximum cell density for the three sterols tested: campesterol > ergosterol $>$ cholesterol. The minimum concentration of stigmasterol required to elicit measurable growth also varied with the sparing sterol supplement as follows: $\leq 0.010 \mu \mathrm{g} \mathrm{ml}^{-1}$ in campesterol-supplemented cultures; $\leq 0.020 \mu \mathrm{g} \mathrm{ml}^{-1}$ in 


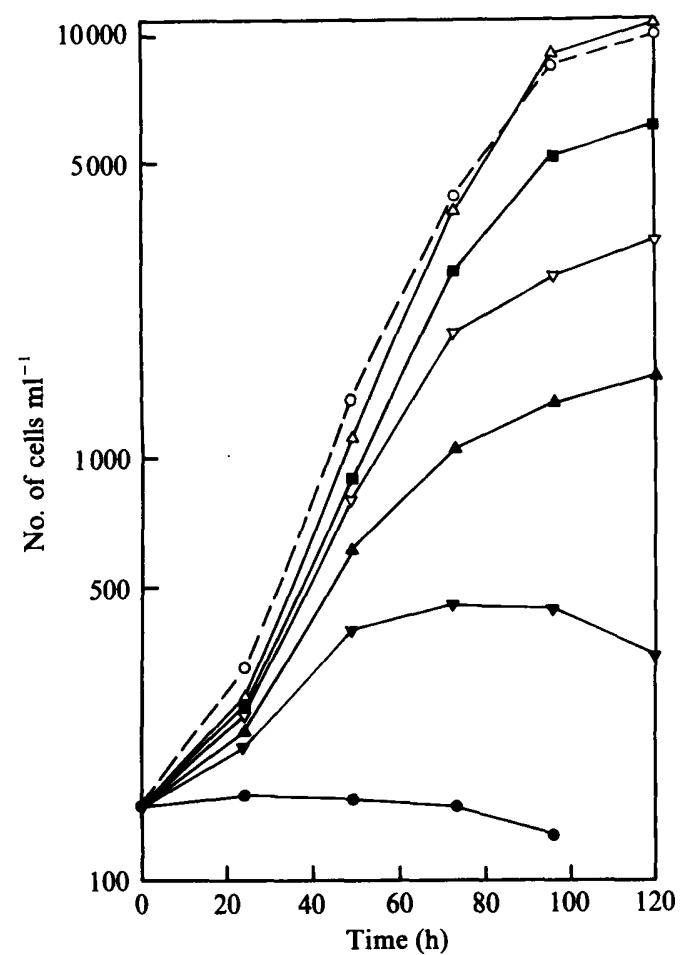

Fig. 4

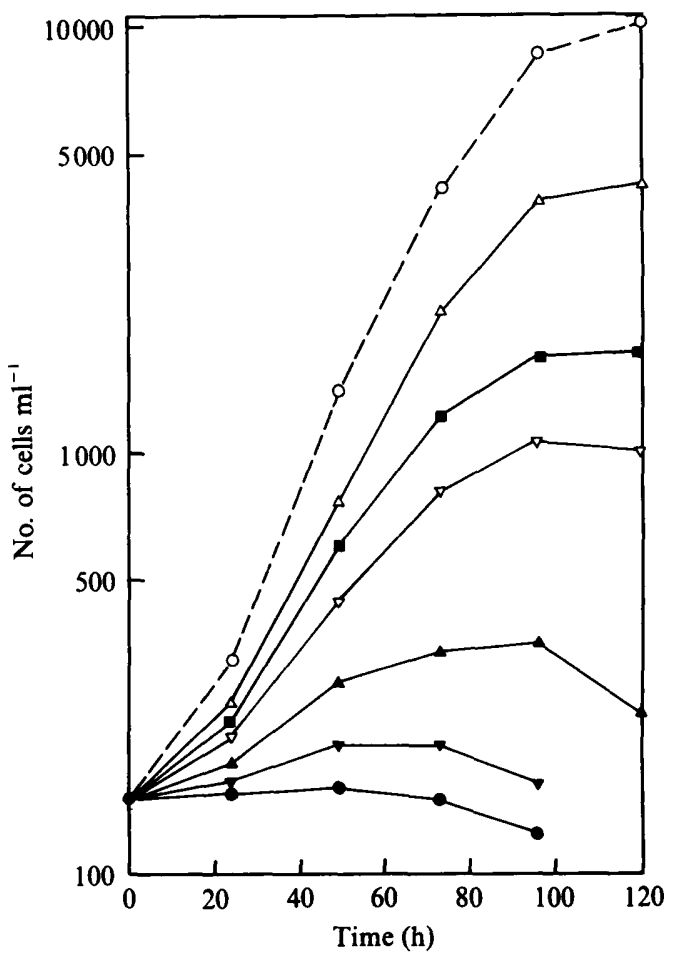

Fig. 5

Fig. 4. Sparing of the requirement for stigmasterol by campesterol in axenic cultures of $P$. tetraurelia at $28^{\circ} \mathrm{C}$. Erlenmeyer flasks $(250 \mathrm{ml})$ containing $50 \mathrm{ml}$ sterile, 'cholesterol-free' Soldo's crude axenic medium (see Methods), plus the specified concentrations of campesterol and stigmasterol, were inoculated at $\approx 150$ cells $\mathrm{ml}^{-1}$ at time zero. The inoculum $(\approx 1.0 \mathrm{ml})$ was drawn from an early stationary-phase culture ( $96 \mathrm{~h}$ growth; $\approx 7.5 \times 10^{3}$ cells $\mathrm{ml}^{-1}$ ) supplemented with $1.0 \mu \mathrm{g}$ campesterol $\mathrm{ml}^{-1}$ plus $0.2 \mu \mathrm{g}$ stigmasterol ml-1. (Thus, the actual concentration of stigmasterol in sparing experiments was $\approx 0.004 \mu \mathrm{g} \mathrm{ml}^{-1}$ higher than the specified concentration.) SD values (not shown) were in the same range as indicated for sparing experiments with monoxenic cultures $(n=3$, with replicate cultures in each experiment). Stigmasterol control (--O--) $1.0 \mu \mathrm{g} \mathrm{ml}^{-1}$. Campesterol at $1.0 \mu \mathrm{g} \mathrm{ml}^{-1}$ (O); plus stigmasterol at $0.010(\nabla), 0.025(\Lambda), 0.050(\nabla), 0.100(\square)$ and $0.250(\triangle) \mu \mathrm{g} \mathrm{ml}^{-1}$.

Fig. 5. Sparing of the requirement for stigmasterol by ergosterol in axenic cultures of $P$. tetraurelia at $28^{\circ} \mathrm{C}$. Erlenmeyer flasks $(250 \mathrm{ml})$ containing $50 \mathrm{ml}$ sterile, 'cholesterol free' Soldo's crude axenic medium (see Methods), plus the specified concentrations of ergosterol and stigmasterol, were inoculated at $\approx 150$ cells $\mathrm{ml}^{-1}$ at time zero. The inoculum $(\approx 2.5 \mathrm{ml})$ was drawn from an early stationary-phase culture ( $96 \mathrm{~h}$ growth; $\approx 3.0 \times 10^{3}$ cells ml $^{-1}$ ) supplemented with $1.0 \mu \mathrm{g}$ ergosterol ml $^{-1}$ plus $0.2 \mu \mathrm{g}$ stigmasterol $\mathrm{ml}^{-1}$. (Thus, the actual concentration of stigmasterol in sparing experiments was $\approx 0.010 \mu \mathrm{g} \mathrm{ml}^{-1}$ higher than the specified concentration.) SD values (not shown) were in the same range as indicated for sparing experiments with monoxenic cultures $(n=3$, with replicate cultures in each experiment). Stigmasterol control (--O--) $1.0 \mu \mathrm{g} \mathrm{ml}^{-1}$. Ergosterol at $1.0 \mu \mathrm{g} \mathrm{m}^{-1}(O)$; plus stigmasterol at $0.010(\nabla), 0.025(\Lambda), 0.050(\nabla), 0.100(\square)$ and $0.250(\triangle) \mu \mathrm{g} \mathrm{ml}^{-1}$.

ergosterol-supplemented cultures; and $\approx 0.025 \mu \mathrm{g} \mathrm{ml}^{-1}$ in cholesterol-supplemented cultures. Thus, growth support at both the maximum and threshold ratios of stigmasterol to sparing sterol was greatest with campesterol, intermediate with ergosterol, and poorest with cholesterol.

\section{DISCUSSION}

The observed differences in growth support by the sparing sterols campesterol, ergosterol, cholesterol and tetrahymanol may reflect their relative suitability for the bulk membrane structural function, their relative level of (weak) growth support, or both. Solubility in the 


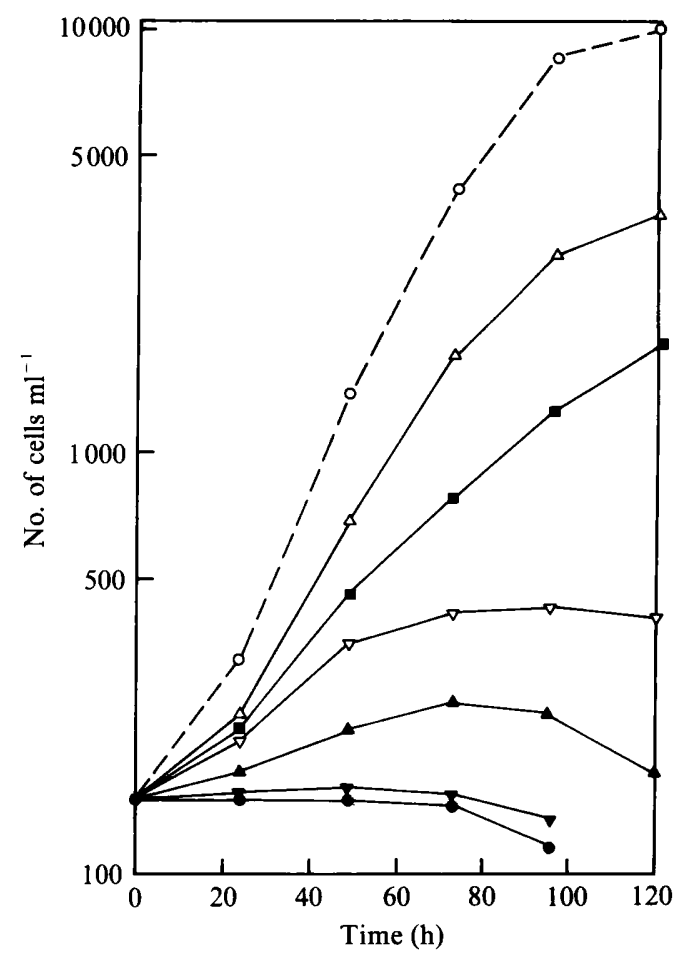

Fig. 6. Sparing of the requirement for stigmasterol by cholesterol in axenic cultures of $P$. tetraurelia at $28^{\circ} \mathrm{C}$. Erlenmeyer flasks $(250 \mathrm{ml})$ containing $50 \mathrm{ml}$ sterile, 'cholesterol free' Soldo's crude axenic medium (see Methods) plus the specified concentrations of cholesterol and stigmasterol, were inoculated at $\approx 150$ cells $\mathrm{ml}^{-1}$ at time zero. The inoculum $(\approx 3.0 \mathrm{ml})$ was drawn from an early stationary-phase culture $\left(96 \mathrm{~h}\right.$ growth; $\approx 2.5 \times 10^{3}$ cells $\left.\mathrm{ml}^{-1}\right)$ supplemented with $1.0 \mu \mathrm{g}$ cholesterol $\mathrm{ml}^{-1}$ plus $0.2 \mu \mathrm{g}$ stigmasterol $\mathrm{ml}^{-1}$. (Thus, the actual concentration of stigmasterol in sparing experiments was $\approx 0.012 \mu \mathrm{g} \mathrm{ml}^{-1}$ higher than the specified concentration.) SD values (not shown) were in the same range as indicated for sparing experiments with monoxenic cultures $(n=3$, with replicate cultures in each experiment). Stigmasterol control $\left(--\mathrm{O}_{--}\right) 1.0 \mu \mathrm{g} \mathrm{ml}^{-1}$. Cholesterol at $1.0 \mu \mathrm{g} \mathrm{ml}^{-1}$ $(\bigcirc)$; plus stigmasterol at $0.010(\nabla), 0.025(\Delta), 0.050(\nabla), 0.100(\square)$ and $0.250(\triangle) \mu \mathrm{g} \mathrm{ml}^{-1}$.

aqueous medium may also be involved in the apparent effectiveness of these four sterols, cholesterol being far more soluble than either campesterol or ergosterol, and these two in turn being more soluble than the triterpenoid alcohol tetrahymanol. It is noteworthy that the threshold concentration of stigmasterol required to elicit measurable growth in the presence of $1.0 \mu \mathrm{g}$ cholesterol ml-1 was significantly lower in monoxenic cultures $\left(\approx 0.015-0.020 \mu \mathrm{g} \mathrm{ml}^{-1}\right)$ than in axenic cultures $\left(\approx 0.025 \mu \mathrm{g} \mathrm{ml}^{-1}\right)$. This could be related to the observed initial lag phase following inoculation of axenic cultures and may reflect a difference in the relative 'availability' of exogenous sterols in the different media.

The demonstration of sterol sparing or synergism in $P$. tetraurelia indicates that the nutritional requirement for specific phytosterols is not related to the structural role of bulk sterol in the cell membrane. There is a growing body of evidence that specific sterols are required in relatively small amounts by micro-organisms, invertebrates and vertebrates to fulfil previously unknown metabolic or regulatory functions (Bloch, 1983).

To summarize what is known about the metabolic or regulatory roles of sterols in several organisms, it has been found in one or more instances that specific sterols have some critical function in fatty acid transport and/or phospholipid biosynthesis (Holz et al., 1962; Dahl et al., 1980, 1981 ; Guyer \& Bloch, 1983), and in respiration/mitochondrial activity (van Wagtendonk 
\& Wulzen, 1950; Conner, 1957; Conner \& Nakatani, 1958; Parks, 1978). For Paramecium, an apparent link between growth support and fatty acyl esterification of sterols has been reported (Conner et al., 1971). This would clearly favour a hypothesis involving essential sterols in the transport, metabolism or transacylation of fatty acids. However, results from our study of sterol nutrition and metabolism in $P$. tetraurelia indicate that fatty acyl esterification is probably not related to the vital function of selected phytosterols in this ciliate (Whitaker \& Nelson, 1987). An intriguing question awaiting further investigation is whether it is the growth-supporting phytosterol per se or instead a metabolite which is required for growth of Paramecium.

This work was supported by grant no. BNS-8100832 from the National Science Foundation to D.L.N.

\section{REFERENCES}

BLOCH, K. E. (1983). Sterol structure and membrane function. Critical Reviews in Biochemistry 14, 47-92.

CONNER, R. L. (1957). Interaction of stigmasterol and 2,4-dinitrophenol in the growth of Tetrahymena piriformis. Science 126, 698.

CONNER, R. L. \& NAKaTANI, M. (1958). Stigmasterol antagonism of certain growth inhibitors for Tetrahymena pyriformis. Archives of Biochemistry and Biophysics 74, 175-181.

CONNER, R. L. \& VAN Wagtendonk, W. J. (1955). Steroid requirements of Paramecium aurelia. Journal of General Microbiology 12, 31-36.

CONNER, R. L., van Wagtendonk, W. J. \& Miller, C. A. (1953). The isolation from lemon juice of a growth factor of steroid nature required for growth of a strain of Paramecium aurelia. Journal of General Microbiology 9, 434-439.

CONNER, R. L., LANDReY, J. R., Kaneshiro, E. S. \& VAN WAGTENDONK, W. J. (1971). The metabolism of stigmasterol and cholesterol by Paramecium aurelia. Biochimica et biophysica acta 239, 312-319.

DAHL, J. S., DAHL, C. E. \& BLOCH, K. (1980). Sterols in membranes: growth characteristics and membrane properties of Mycoplasma capricolum cultured on cholesterol and lanosterol. Biochemistry 19, 14671472.

DAHL, J. S., DAHL, C. E. \& BLOCH, K. (1981). Effect of cholesterol on macromolecular synthesis and fatty acid uptake by Mycoplasma capricolum. Journal of Biological Chemistry 256, 87-91.

GUYER, W. \& BLOCH, K. (1983). The sterol requirement of Tetrahymena setosa HZ-1. Journal of Protozoology 30, 625-629.

Holz, G. G., JR, Erwin, J., Wagner, B. \& RosenBAUM, N. (1962). The nutrition of Tetrahymena setifera $\mathrm{HZ}-1$ : sterol and alcohol requirements. Journal of Protozoology 9, 359-363.
PARKS, L. W. (1978). Metabolism of sterols in yeast. Critical Reviews in Microbiology 6, 301-341.

Pinto, W. J., Lozano, R., Sekula, B. C. \& Nes, W. R. (1983). Stereochemically distinct roles for sterol in Saccharomyces cerevisiae. Biochemical and Biophysical Research Communications 112, 47-54.

PITT, M. W. (1980). A study of the growth of Paramecium tetraurelia in bacterized culture. MS thesis, University of Wisconsin-Madison.

RAMPOGAL, M. \& BLOCH, K. (1983). Sterol synergism in yeast. Proceedings of the National Academy of Sciences of the United States of America 80,712-715.

SOLDO, A. T. \& VAN WAGTENDONK, W. J. (1967). An analysis of the nutritional requirements for fatty acids of Paramecium aurelia. Journal of Protozoology 14, 596-600.

Soldo, A. T. \& VAN WagtendonK, W. J. (1969). The nutrition of Paramecium aurelia, stock 299. Journal of Protozoology 16, 500-506.

SonNEborn, T. M. (1975). Species designations and descriptions of the 14 syngens of Paramecium aurelia. Transactions of the American Microbiological Society 94, $155-178$.

VAN WAgtendonk, W. J. \& Wulzen, R. (1950). Physiological and chemical aspects of the antistiffness factor essential for guinea pigs. Vitamins and Hormones 8, 69-125.

van Wagtendonk, W. J., Conner, R. L., Miller, C. A. \& RAO, M. R. R. (1953). Growth requirements of Paramecium aurelia var. 4, stock 51.7, sensitives and killers, in axenic medium. Annals of the New York Academy of Sciences 56, 929-937.

WhitAKer, B. D. \& Nelson, D. L. (1987). Growth support and metabolism of phytosterols in Paramecium tetraurelia. Lipids 22, 386-396. 